\title{
MEMBANGUN WEBSITE SORGUM SEBAGAI SARANA PROMOSI PUSAT PENELITIAN DAN PENGEMBANGAN SORGUM DI UNIVERSITAS WIJAYA KUSUMA SURABAYA
}

\author{
Tjatursari Widiartin \\ Fakultas Teknik, Program Studi Teknik Informatika \\ Universitas Wijaya Kusuma Surabaya \\ Email: widiartin@gmail.com \\ Endang Noerhartati \\ Fakultas Teknik, Program Studi Teknologi Ilmu Pertanian \\ Universitas Wijaya Kusuma Surabaya \\ Email: endang.noerhartati@gmail.com
}

\begin{abstract}
ABSTRAK
Saat ini, sorgum sudah menjadi penelitian unggulan Universitas wijaya kusuma Surabaya dengan menjadikan Universitas sebagai sebuah pusat penelitian dan pengembangan sorgum. Agar keberadaannya sebagai lembaga yang menjadi pusat penelitian dan pengembangan sorgum dikenal luas, maka perlu dilakukan sebuah promosi. Sistem promosi online dikenal sebagai sistem promosi yang lebih cepat dikenal masyarakat dan lebih cepat juga menarik perhatian masyarakat. Maka dalam penelitian ini akan dibangun sebuah website promosi. Sistem website promosi dibangun dengan menggunakan metode Software Development Life Cycle (SDLC) 4 fase. Dari penelitian dihasilkan sebuah website promosi dengan domain ifasorgum.com dengan halaman yang telah diklasifikasikan yaitu: (1) memuat informasi mengenai penelitian sorgum yang telah dilakukan, (2) Kerjasama yang telah dilakukan dalam pengembangan sorgum, (3) Inkubator yang dimiliki Universitas agar kewirausahaan sorgum berkembang, dan sebagainya, (4)Promosi berbagai produk variasi olahan yang dibuat dari sorgum.
\end{abstract}

Kata kunci: sorgum, promosi, online, website, SDLC, pusat penelitan, pengembangan.

\section{ABSTRACT}

Currently, sorghum has become a leading research university wijaya kusuma Surabaya by making the University as a center of research and development of sorghum. In order for the availability of institutions that become centers of research and development of sorghum widely known, it is necessary to do a promotion. An online promotion system is known to be a faster promotional system known to the public and more quickly also attracts the public. So in this research will be built a promotional website. Promotional website system is built using 4 phase Software Development Life Cycle (SDLC) method. From the research resulted a promotion website with domain ifasorgum.com with classified page that is: (1) contains information about sorghum research which have been done, (2) Cooperation which have been done in sorghum development, (3) Incubator owned by University for entrepreneurship sorghum flourish, and so on, (4) Promotion of various processed product variations made from sorghum.

Keywords: sorghum, promotion, online, website, SDLC, research center, development.

\section{PENDAHULUAN}

Sorgum adalah sebuah pangan alternatif dan sudah banyak negara yang membudidayakannya termasuk negara Ethiopia[1]. Bahkan di Cina tanaman ini sengaja diperkenalkan sebagai kebutuhan makanan[2]. Selain sebagai alternative pangan, sorgum juga termasuh salah satu bahan pangan yang memiliki kadar antioksidan tinggi[3]. Oleh sebab itu, Sejak tahun 2009, UWKS telah memulai penelitianpenelitian mengenai "Pengembangan Sorgum Sebagai Pangan Alternatif"[4], dimana hasil penelitian menunjukkan bahwa sorgum dapat diolah menjadi mi instan, digunakan sebagai pensubstitusi aneka tepung: tepung terigu, tepung ketan, maupun tepung beras, dll. Dimulai dari biji yang dapat diolah menjadi beras, tepung, bekatul, aneka produk olahan tepung menjadi aneka kue basah: nagasari, lapis, sosis solo, onde-onde, dan lain-lain, serta aneka kue kering: stik, pie, dan aneka cookies, serta masih ada hasil penelitian dari batang sorgum yang dapat diolah menjadi sirup batang sorgum. Pada waktu yang bersamaan UWKS melakukan kerjasama dan membentuk jaringan produsen sorgum di beberapa daerah 
di Pulau Jawa. Dalam kaitan itu pula UWKS telah menetapkan daerah binaan dan memilih beberapa kelompok tani sorgum di Kabupaten di Jawa Timur sebagai mitra pengembangan produk-produk olahan sorgum yaitu Kabupaten Lamongan, Bangkalan, Sampang, Probolinggo, Pasuruan, Bojonegoro, dan Pacitan.

Produk pangan berbasis sorgum saat ini belum ada di pasaran, yang ada hanya diberbagai tempat untuk kegiatan-kegiatan pameran, sehingga kompetitor produk sorgum bisa disimpulkan bahwa belum ada.

Berdasarkan hal tersebut, maka Universitas Wijaya Kusuma memerlukan sebuah sarana promosi yang dapat memperkenalkan seluruh kegiatan penelitian dan pengembangan produk sorgum yang telah dilakukan oleh UWKS. Membangun sebuah sistem promosi online adalah langkah yang tepat. Karena sistem promosi online akan dapat mempengaruhi minat seseorang atau Masyarakat terhadap informasi atau produk yang dipromosikan[5].

Website adalah sekumpulan halaman yang berisi informasi dan dipublikasikan dengan menggunakan teknologi internet sehingga dapat diakses dimanapun manusia berada, dan dapat diakses setiap waktu. Dengan membangun sebuah website promosi, maka masyarakat akan mengetahui bahwa telah ada sebuah pusat penelitian dan pengembangan sorgum, yaitu di Universitas Wijaya Kusuma Surabaya. Selain itu manfaat lainnya dengan adanya website promosi nantinya adalah Masyarakat akan mengetahui manfaat dari sorgum dan aneka olahan yang terbuat dari sorgum. Dengan adanya website promosi juga dapat menginformasikan ke Masyarakat bahwa banyak sumber pangan alternatif yang potensial dapat dikembangkan untuk mendukung program diversifikasi dan ketahanan pangan bangsa Indonesia, satu diantaranya adalah sorgum (Sorghum Sp). Sorgum sebagai sumber pangan dunia berada di peringkat ke-5 setelah gandum, padi, jagung dan barley. Bila kelembaban tanah bukan merupakan faktor pembatas, hasil sorgum rata-rata dapat mencapai 5-6 ton/ha. Di Indonesia sorgum telah lama dikenal oleh petani khususnya di Jawa, NTB dan NTT, khusus di Jawa Timur produksi sorgum terbesar di daerah Bojonegoro, Lamongan, Blitar, dan Lumajang. Sorgum memiliki kandungan nutrisi yang baik, selain karbohidrat, protein, lemak juga mengandung mineral kalsium, besi, pospor, dan vitamin $B_{1}$, Berdasarkan hal tersebut maka sorgum dapat digunakan sebagai alternatif sumber pangan. Sorgum dapat digunakan sebagai bahan baku untuk produk setengah jadi yang diarahkan untuk memperkaya potensi sorgum, yaitu tepung sorgum. Dari beras sorgum dan tepung sorgum selanjutnya dapat diolah menjadi bermacam aneka olahan dari bahan sorgum[6].

Sebuah website dapat dibangun dengan platform yang beragam, dan dengan menggunakan Bahasa pemrograman yang beragam pula. Salah satu Bahasa pemrograman yang dapat digunakan adalah dengan menggunakan Bahasa pemrograman PHP[7].

Sebuah website membutuhkan teknologi internet agar dapat diakses secara luas. Kebutuhan teknologi internet adalah untuk menyediakan sebuah domain dan sebagai wadah hosting dari domain website tersebut. Biasanya sebuah domain akan menjadi sebuah nama dari website yang akan dipublikasikan. Dan pengguna website tidak begitu memperdulikan dengan permasalahan hosting sebuah domain.

\section{METODOLOGI PENELITIAN}

Dalam membangun website digunakan metode Software Development Life Cycle (SDLC) 4 Pase[8], yaitu: Analisa Sistem, Desain Sistem, Implemenasi Sistem, dan Testing Sistem. Pada metode SDLC, setiap pase yang dijalankan merupakan sebuah siklus berulang, sehingga metode ini menjadi lebih fleksibel dibandingkan metode yang lainnya[9].

\subsection{Analisa Dan Desain Website Promosi Sorgum}

Membangun website pada dasarnya melalui beberapa tahapan. Klasifikasi tahapan yang diperlukan tergantung pada jenis website yang akan dibangun. Pada penelitian ini, untuk website promosi sorgum yang akan dibangun adalah website statis. tahapan yang diperlukan dalam mebangun website promosi sorgum adalah sebagai berikut:

a) Desain Web dengan menggunakan Web Builder[10]

b) Melakukan Coding untuk mempublikasikan web yang telah didesain. Editor yang digunakan untuk coding dengan menggunakan aplikasi Webmatrix[11]

c) Setting Domain 


\subsection{Implementasi Domain Sorgum}

Pada saat page-page yang kita bangun telah siap untuk dionlinekan, maka diperlukan sebuah domain untuk menampung page-page tersebut. Pada penelitian ini, domain yang akan diset diberi nama dengan "ifasorgum.com".

Untuk mengatur page-page yang kita miliki maka dilakukan pengelolaan terhadap domain "ifasorgum.com" dengan masuk ke akun yang kita miliki melalui https://cpanel.hostinger.co.id/ seperti ditunjukkan padaa gambar 1, yaitu[12]:

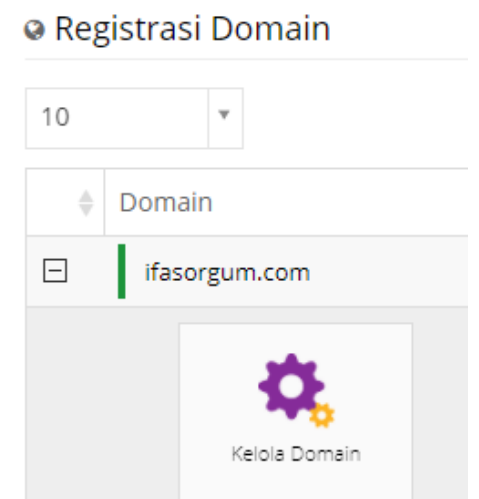

Gambar 1. Menu Untuk Melakukan Kelola Domain "ifasorgum.com”

\subsection{Hosting Domain Sorgum}

Agar domain yang diset dapat dionlinekan, maka tahapan selanjutnya adalah melakukan proses hosting untuk domain yang ingin dionlinekan. Hosting sendiri adalah proses untuk meletakkan atau memasukkan seluruh file website yang sudah dibuat. Langkah awal untuk melakukan memindahkan file adalah dengan memilih menu import website seperti ditunjukkan pada gambar 2 .

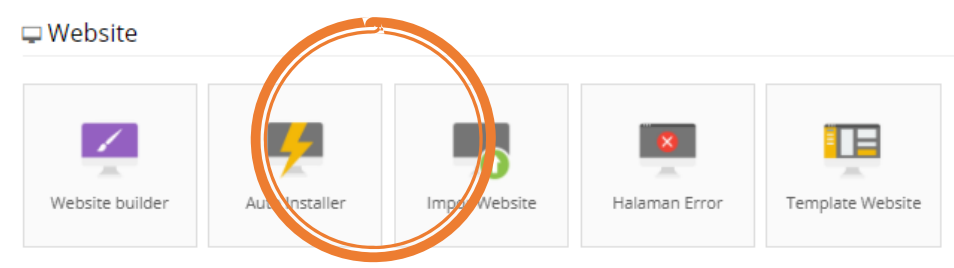

\section{Gambar 2. Menu Pada Control Panel Untuk Memasukkan File Website}

Langkah berikutnya adalah dengan menyiapkan file yang akan diunggah dengan menjadikan satu paket seluruh file kedalam file terkompresi dengan format zip. Cara memasukkan file kedalam server seperti ditunjukkan pada gambar 3. Apabila seluruh file telah diunggah, selanjutnya adalah melakukan uji coba website dengan menjalankan domain "ifasorgum.com" pada browser.

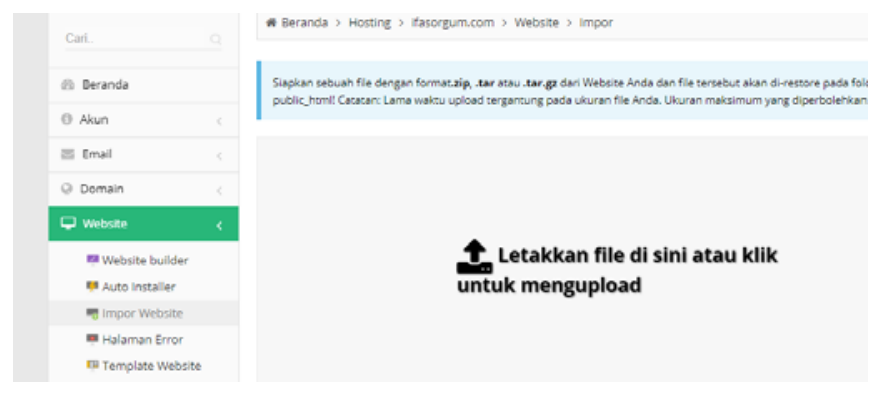

Gambar 3. Editor Untuk Unggah File-File Website 


\section{HASIL DAN PEMBAHASAN}

\subsection{Web Ifasorgum.Com}

Hasil penelitian adalah website promosi sorgum dionlinekan di internet agar dapat diakses oleh siapapun, dan kapanpun. Tampilan utama website "ifasorgum.com" seperti ditunjukkan pada gambar 4.

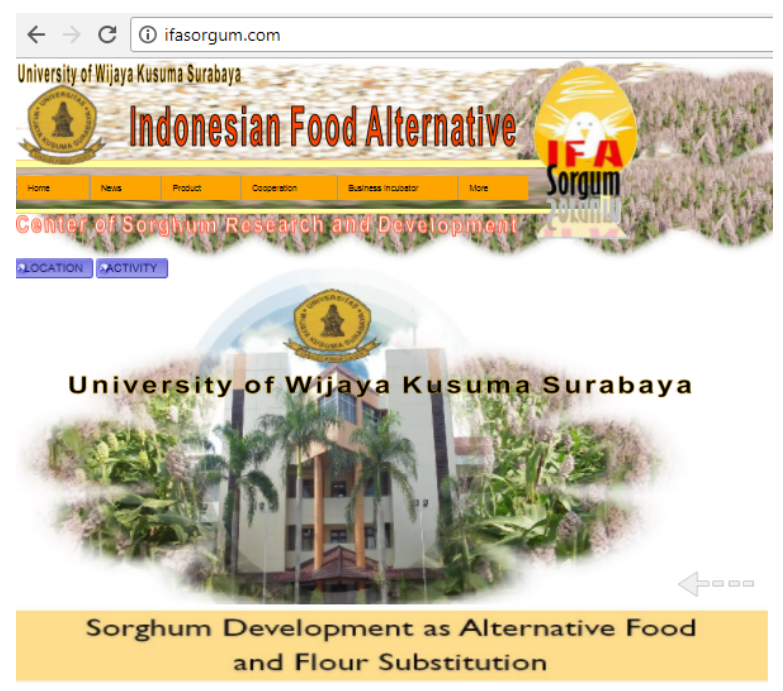

Gambar 4. Tampilan Utama Website "ifasorgum.com"

\subsection{Komponen Website ifasorgum.com}

Pada website promosi sorgum yang dibangun memiliki beberapa komponen sesuai dengan tema informasi yang ingin disampaikan. Komponen website "ifasorgum.com", yaitu:

a) News

Komponen news digunakan untuk memberi informasi mengenai kegiatan yang telah dilakukan oleh Universitas Wijaya Kusuma berkaitan dengan penelitian dan pengembangan yang telah dilakukan terhadap sorgum, seperti ditunjukkan pada gambar 5. Didalam komponen News tersebut ditampilkan informasi mengenai "Community Service", "Expert", "Seminar", "Training", "Award", dan "Another Link".

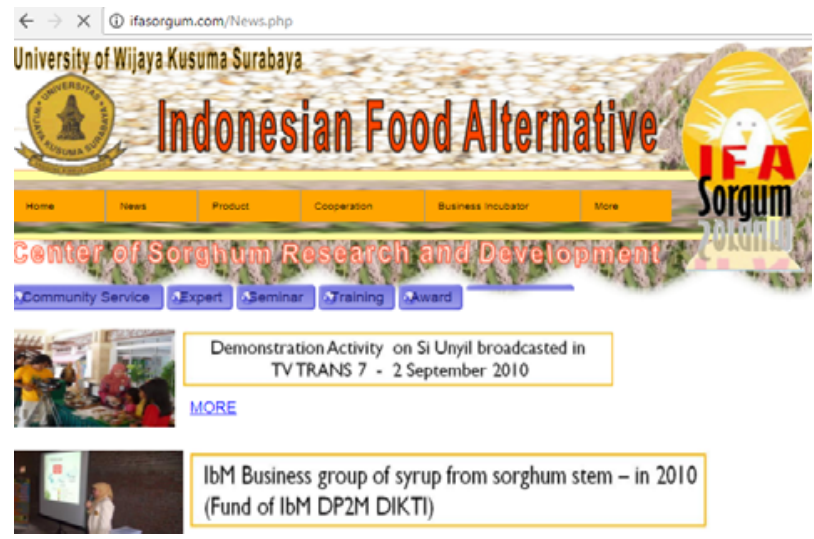

Gambar 5. Komponen News Pada Domain "ifasorgum.com"

b) Product

Komponen product digunakan untuk memberi informasi mengenai produksi yang dapat dihasilkan pada sorgum, yaitu aneka olahan yang dihasilkan dari sorgum, seperti ditunjukkan pada gambar 6. 


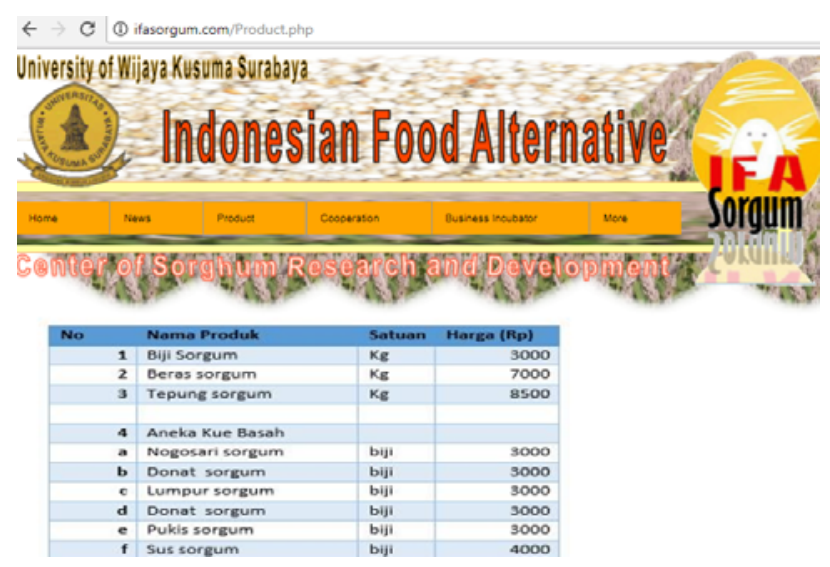

Gambar 6. Komponen Product Pada Domain "ifasorgum.com"

c) Cooperation

Komponen Cooperation digunakan untuk memberi informasi mengenai kerjasama yang telah dilakukan oleh Universitas Wijaya Kusuma Surabaya, yaitu kerjasama yang telah dilakukan didalam negeri dan kerjasama internasional, seperti ditunjukkan pada gambar 7 .

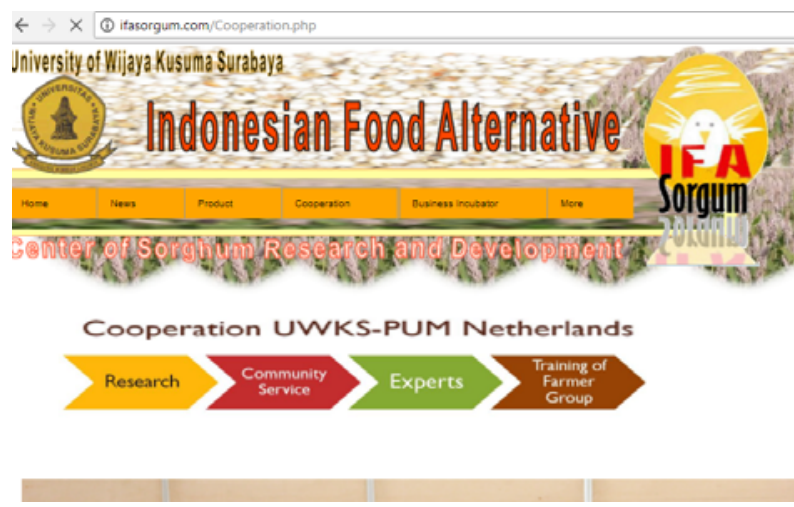

\section{Gambar 7. Komponen Cooperation Pada Domain "ifasorgum.com"}

d) Business Incubator

Komponen Business Incubator digunakan untuk memberi informasi mengenai aktifitas inkubator yang telah dilakukan oleh Universitas Wijaya Kusuma dalam mengembangkan entrepreneurship dalam pengembangan sorgum, seperti ditunjukkan pada gambar 8 .

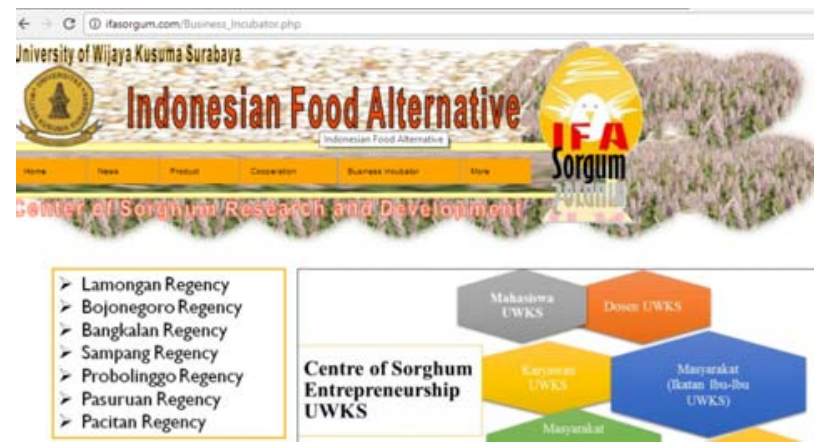

Gambar 8. Komponen Business Incubator Pada Domain "ifasorgum.com" 


\section{KESIMPULAN}

Dengan adanya website promosi sorgum, maka Universitas Wijaya Kusuma dapat menampilkan informasi mengeni aktifitas penelitian dan pengembangan sorgum. Sebaliknya, Masyarakat akan dapat mengakses informasi tersebut, sehingga keberadaan sorgum sebagai produk unggulan Universitas Wijaya Kusuma Surabaya dapat diketahui.

\section{DAFTAR PUSTAKA}

[1] Wondewosen Siferow, 2014, "Collection, Characterization, and Evaluation of Sorghum (sorghum bicolor (L.) Moench) Landraces from South Omo and segen peoples Zone of South Nation Nationality People Region Ethiopia”, International Research Journal of Agricultural Science and Soil Science, Vol. 4(4) pp. 7684

[2] Cheick Oumar Kangama, 2005, "Introduction of sorghum (Sorghum bicolor (L.) Moench) into China”, African Journal of Biotechnology Vol. 4 (7), pp. 575-579

[3] Pasha Imran, 2014, "Exploring the Antioxidant Perspective of Sorghum and Millet", Journal of Food Processing and Preservation, Volume 39, Issue 6 December 2015 Pages 1089-1097

[4] Endang Noerhartati, 2010. Aneka Produk Industri Berbahan Baku Gandum dan Sorgum. Makalah Temu Usaha Dan Temu Teknologi”. Dinas Pertanian Pemerintah Provinsi Jawa Timur 27-28 Juli, 2010 - Batu Malang

[5] Jamaludin Achmad, 2015, "Pengaruh Promosi Online dan Persepsi Harga Terhadap Keputusan Pembelian”, Jurnal Administrasi Bisnis (JAB)|Vol. 21 No. 1 April 2015|, Hal 1-8

[6] Endang Noerhartati, 2010. Aneka Cookies Berbahan BakuTepung Sorgum (Sorghum bicolor). Makalah "Liputan Si Unyil TV TRANS 7". Kerjasama Program Studi Teknologi Industri Pertanian Fakultas Teknik-Universitas Wijaya Kusuma Surabaya dengan Liputan Si Unyil TV TRANS 7. (2 September 2010)

[7] Welling Luke, and Thompson Laura, 2009, "PHP and MySQLWeb Development", Fourth Edition, Pearson Education Inc

[8] Kendall, and Kendal, 2005, "System Analysis and Design”, Sixth Edition, Prentice Hall

[9] Scroggins Richard, 2014, "SDLC and Development Methodologies", Global Journal of Computer Science and Technology: C Software \& Data Engineering, Volume 14 Issue 7, pp 20-22

[10] Software Web Builder Versi 11.

[11] Sofware Microsoft Webmatrix

[12] Situs Hostinger.co.id 